\title{
Contribuições da teoria histórico-cultural para uma educação infantil como lugar das crianças e infâncias
}

\author{
Ligia Maria Leão de Aquino $\star$ \\ Universidade do Estado do Rio de Janeiro, Rio de Janeiro, RJ, Brasil
}

\begin{abstract}
Resumo
O artigo traz reflexões sobre contribuições da teoria histórico-cultural para pensar o papel da educação infantil na sociedade contemporânea. Identifica-se como avanço o processo de institucionalização da educação infantil com sua efetiva integração ao sistema de ensino, o que exige reconhecer as especificidades da infância para se evitar uma simples conformação dessa etapa educacional ao modelo e finalidade da educação escolar de ensino fundamental. Recorre-se à perspectiva histórico-cultural como suporte teórico para afirmar a educação infantil com finalidade de promover o desenvolvimento integral da criança, como preconiza a Lei de Diretrizes e Bases da Educação Nacional (LDB). Estudos vigotskianos sobre a importância da brincadeira para o desenvolvimento humano e sobre os processos de desenvolvimento do pensamento e sua relação com a fala fornecem elementos para se afirmar a brincadeira e as interações como eixos norteadores das propostas pedagógicas destinada a crianças de zero a seis anos.
\end{abstract}

Palavras-chave: educação infantil; teoria histórico-cultural; desenvolvimento infantil.

\section{Contributions of the Historical-cultural theory to an early childhood education as a children and childhood place}

\begin{abstract}
This article brings reflections about contributions of the historical-cultural theory in thinking about the role of childhood education on modern society. Identifies as a progress the process of institutionalization of childhood education with its effective integration to the education system, which requires the peculiarities of childhood to avoid a simple conformation in this educational stage to the model and finality of basic school education. Arrangements are made to the perspective of the historical-cultural theory as a teorical support to reaffirmation of childhood education with the finality of promoting the generate development among children, as symbolized by the Law of Directives and Basis for National Education (LDB). Vygotskian studies about the importance of play for human development e about process of development of thinking and your relation with speech provide elements to affirm that playing and the interactions as the guiding principles of the pedagogic proposes designated to children between 0 and 6 years old.
\end{abstract}

Keywords: childhood education; Historical-Cultural Theory; childhood development.

O presente texto traz reflexões sobre contribuições da teoria histórico-cultural para pensar o papel da educação infantil na sociedade contemporânea. Tais reflexões são compartilhadas pelo Grupo de Pesquisa Infância e Saber Docente, no qual adotamos uma abordagem multidisciplinar, dialogando com diferentes áreas e estudos que permitem a compreensão da infância como construção social. Em nossas investigações, privilegiamos como lócus de análise as instituições educacionais destinadas à criança, em especial, as creches e pré-escolas, reconhecendo os profissionais docentes como sujeitos fundamentais da ação educacional dessas instituições. Desenvolvemos, desde 2010, pesquisa sobre a produção do conhecimento sobre a infância em unidades universitárias de educação infantil (AQUINO, 2010, 2012), contando com bolsa de Prociência - UERJ/FAPERJ e de Jovem Cientista de Nosso Estado - FAPERJ, a qual se integram estudos de doutorado e mestrado, concluídos e em andamento (BARROS, 2013; OLIVEIRA, D., 2014; SANTOS, 2013; MELO, 2013; REIS, 2013; MENEZES, 2014).

\footnotetext{
* Coordenadora do Grupo de Pesquisa Infância e Saber Docente, vinculado à Linha de Pesquisa Infância, Juventude e Educação do Programa de PósGraduação em Educação (PROPEd) da Universidade do Estado do Rio de Janeiro (UERJ). Endereço para correspondência: Universidade do Estado do Rio de Janeiro, Faculdade de Educação. R. São Francisco Xavier, 524 sl 12037 F - Maracanã. CEP: 20550900 - Rio de Janeiro, RJ - Brasil

E-mail: ligiaaquino@yahoo.com.br
}

Em nossos estudos, reconhecemos que nas últimas décadas a educação infantil tem sido efetivamente integrada ao sistema de ensino, passando a fazer parte de ações e verbas públicas de diversas políticas educacionais, como, por exemplo, na esfera federal, o Programa Nacional de Biblioteca da Escola, com acervo de literatura infantil específico para as crianças pequenas, o Programa Nacional de Alimentação Escolar, o Programa Nacional de Reestruturação e Aparelhagem da Rede Escolar Pública de Educação Infantil (Proinfância) e programas de apoio às universidades para desenvolvimento de cursos de graduação e pós-graduação destinados a docentes da educação infantil. Essas ações se constituem num avanço para a institucionalização da educação infantil com caráter educacional, entretanto, observamos que tal integração ao sistema de ensino tem acentuado discursos e propostas de conformação dessa etapa educacional ao modelo e finalidade da educação escolar de ensino fundamental, como a organização curricular por disciplinas escolares e sistemas de avalição para as crianças. Nessa mesma direção, vemos o retorno a concepções de "pré-escola" preparatória para a escolaridade de ensino fundamental, com a antecipação de conteúdos das disciplinas e uma forte ênfase na alfabetização das crianças em idade pré-escolar.

Em sentido oposto à concepção preparatória, afirmamos a educação infantil como um lugar das crianças e das infâncias. Uma proposta que vai além do que idealizou 
Montessori com sua Casa da Criança, pois ao tomarmos a infância como possibilidade, potência, o tempo/espaço da não fala e da fala que se inaugura, da criação e como tempo de experiência, defendemos a educação infantil como lugar de potência e criação para as crianças e suas/ seus professoras/es e quem mais compartilha esse espaço/tempo. Essa concepção se aproxima do preconizado na Lei de Diretrizes e Bases da Educação Nacional-LDB (BRASIL, 1996) para a educação infantil, quando se estabelece o "desenvolvimento integral da criança $[. .$. em seus aspectos físico, psicológico, intelectual e social, complementando a ação da família e da comunidade", ${ }^{1}$ como seu objetivo, ao passo que a finalidade de desenvolver a capacidade de aprendizagens específicas, como "o pleno domínio da leitura, da escrita e do cálculo", ${ }^{2}$ entre outras, está definida para o ensino fundamental. Ressaltamos ainda que o caráter de não preparatório também está expresso nesta lei quando se determina que a avaliação não tenha como objetivo a promoção ou retenção das crianças, mas sim a função de fazer "o acompanhamento e registro do desenvolvimento das crianças". ${ }^{3}$ A diferença na orientação e finalidade da educação infantil em relação às etapas seguintes se dá pelo reconhecimento das especificidades dessa fase da vida.

Nos primeiros anos de vida, a criança tem uma forma muito peculiar de se relacionar com o mundo e de conhecer, diferentemente ao que ocorre em idades posteriores (VASCONCELLOS; VALSINER, 1995), o que exige uma educação com características mais integrais, globais, considerando as múltiplas dimensões humanas (corporal, cognitiva, afetiva, linguística, cultural), não se restringindo à transmissão de informações e atividades de instrução, que dão ênfase à cognição (MACHADO, 1995). Desse modo, as Diretrizes Curriculares Nacionais para a Educação Infantil (DCNEI) (BRASIL, 2009) determinaram que cabe à educação infantil garantir a promoção de condições de convivência entre crianças e entre crianças e adultos, visto que nas interações e brincadeiras elas elaboram "sua identidade pessoal e coletiva, brinca[m], ima$\operatorname{gina}[\mathrm{m}]$, fantasia[m], deseja[m], aprende[m], observa[m], experimenta[m], narra[m], questiona[m] e constrói[em] sentidos sobre a natureza e a sociedade, produzindo cultura." (BRASIL, 2010, p. 12).

\footnotetext{
${ }^{1}$ Art. 29. A educação infantil, primeira etapa da educação básica, tem como finalidade o desenvolvimento integral da criança de até 5 (cinco) anos, em seus aspectos físico, psicológico, intelectual e social, complementando a ação da família e da comunidade. (BRASIL, 1996). Redação alterada pela Lei n 12.796, de 4 de abril d 2013, disponível em http://www.planalto.gov.br/ccivil 03/ Ato2011-2014/2013/Lei/L12796.htm\#art1. Acesso em 20 de julho de 2013.

Art. 32. O ensino fundamental obrigatório, com duração de 9 (nove) anos, gratuito na escola pública, iniciando-se aos 6 (seis) anos de idade, terá por objetivo a formação básica do cidadão, mediante: (Redação dada pela Lei $\mathrm{n}^{\circ}$ 11.274, de 2006): I - o desenvolvimento da capacidade de aprender, tendo como meios básicos o pleno domínio da leitura, da escrita e do cálculo; II - a compreensão do ambiente natural e social, do sistema político, da tecnologia, das artes e dos valores em que se fundamenta a sociedade; III - o desenvolvimento da capacidade de aprendizagem, tendo em vista a aquisição de conhecimentos e habilidades e a formação de atitudes e valores; IV - o fortalecimento dos vínculos de família, dos laços de solidariedade humana e de tolerância recíproca em que se assenta a vida social. (BRASIL, 1996).

Art. 31. A educação infantil será organizada de acordo com as seguintes regras comuns: (Redação dada pela Lei $\mathrm{n}^{\circ} 12.796$, de 2013): I - avaliação mediante acompanhamento e registro do desenvolvimento das crianças, sem o objetivo de promoção, mesmo para o acesso ao ensino fundamental; [...] (BRASIL, 1996).
}

As ideias que fundamentam a concepção de uma educação para crianças pequenas sem objetivo de promover aprendizagens específicas são respaldadas em estudos e teorias de diversos campos (OLIVEIRA-FORMOSINHO; KISHIMOTO; PINAZZA, 2007). Na perspectiva da teoria histórico-cultural, encontramos estudos que afirmam a importância da brincadeira para o desenvolvimento do ser humano, para constituição da subjetividade, especialmente nos seus primeiros anos de vida. Outra contribuição dessa corrente teórica se refere aos estudos sobre os processos de desenvolvimento do pensamento e sua relação com a fala.

Vigotski (1979) analisou as especificidades do pensamento da criança e de sua expressão, evidenciando que a diferença entre o modo de pensar e de se expressar entre adultos e crianças, especialmente nos primeiros anos de vida, é de ordem qualitativa, não se trata de uma versão reduzida ou incompleta. A criança não é um adulto em miniatura.

[...] a criança desenvolve equivalentes funcionais dos conceitos numa idade extremamente precoce, mas as formas de pensamento que utiliza ao defrontar-se com estas tarefas diferem profundamente das que o adulto emprega pela sua composição, pela sua estrutura e pelo seu modo de operação (VYGOTSKY, 1979, p. 79-80).

A descoberta que a criança faz, por volta de dois anos de idade, de que todas as coisas têm um nome é um grande marco, pois significa que a criança iniciou o processo de pensar que acabará por produzir, no futuro, os conceitos. Nessa fase, o pensamento se dá pela formação de conceitos espontâneos, também chamados de cotidianos. Os conceitos cotidianos estão relacionados às situações do dia a dia e são formados através das interações sociais imediatas e por meio de atividade prática. Percorrem um longo caminho para se organizarem como conceito de fato.

[...] o desenvolvimento dos processos que acabam por gerar a formação dos conceitos começa durante as fases mais precoces da infância, mas as funções intelectuais que, em determinadas combinações formam a base psicológica da formação do conceito amadurecem, tomam forma e desenvolvem-se apenas durante a puberdade ${ }^{4}$ (VYGOTSKY, 1979, p. 82).

No processo de formação dos conceitos são identificados três momentos. Num primeiro momento, o pensamento é "sincrético", seus elementos constituem um acervo desorganizado e amontoado, reunidos sem qualquer base e com forma instável. O termo "monte" é utilizado para designar o tipo de conceito formado nessa fase. No segundo momento, se dá o "pensamento por complexos" que apresenta coerência e objetivo, embora as ligações que ocorrem entre os componentes de um complexo sejam "mais concretas e factuais do que abstratas e lógicas" (VYGOTSKY, 1979, p. 86). Ainda nesse momento, há um subestágio de extrema importância no desenvolvimento que se processa, pois é a ponte entre o pensamento por complexos e o estágio final: é o "pseudoconceito",

${ }^{4}$ Observe-se que esse desenvolvimento não se dá natural, dependendo de exigências e condições materiais e simbólicas dispostas na sociedade (VYGOTSKY, 1979) 
que se assemelha ao conceito verdadeiro, mas "na sua essência ainda é um complexo" (VYGOTSKY, 1979, p. 86). Sua base está na percepção apesar de já apresentar uma organização quanto à definição de critério único e estável. Por fim, no terceiro momento, ocorre o chamado "pensamento por conceitos". É quando o sujeito torna-se capaz de operar mentalmente de modo que ao mesmo tempo unifique e separe, isto é, realize a combinação da síntese com a análise, o que possibilita produzir conceitos (VYGOTSKY, 1979, p. 104).

Trazendo essa discussão para a educação infantil, observamos que as crianças que frequentam essa etapa educacional e que iniciam a fala operam através da "organização de montes" - ou via pensamento por complexos. Importa destacar que os pseudoconceitos predominam no pensamento da criança em idade pré-escolar (VYGOTSKY, 1979).

Os pseudos-conceitos predominam sobre todos os outros complexos no pensamento da criança em idade pré-escolar, pela simples razão de que, na vida real, os complexos que correspondem ao significado das palavras não são espontaneamente desenvolvidos pela criança: a trajectoria seguida por um complexo no seu desenvolvimento encontra-se pré-determinada pelo significado que determinada palavra já possui na linguagem dos adultos (VYGOTSKY, 1979, p. 92-93).

Em tal processo, por um lado, a criança dispõe dos significados que as palavras já possuem na linguagem dos adultos e, por outro, há “a forma peculiar ao seu nível de desenvolvimento intelectual" (VYGOTSKY, 1979, p. 93). Portanto, a aprendizagem de conceitos não ocorre por simples transmissão ou insistente reprisar de informações; o adulto, ao falar com a criança, apenas apresenta "o significado já acabado de uma palavra, em torno da qual a criança forma um complexo - com todas as peculiaridades estruturais funcionais e genéticas" próprias do seu modo de pensar (VYGOTSKY, 1979, p. 93).

A formação do pensamento verbal e a apropriação dos conceitos não se dão mecanicamente, nem de modo instantâneo. É um longo processo no qual o conceito vai sendo transformado nas diversas situações em que é utilizado e, também, transforma quem o utiliza, ao possibilitar o alargamento das experiências vividas pela capacidade de nomear, evocar, generalizar e orientar o pensamento (VASCONCELLOS, 2001; TUNES, 1995).

[...] o pensamento verbal não é uma forma natural de comportamento, inata, mas é determinado pelo processo histórico-cultural e tem propriedades e leis específicas que não podem ser encontradas nas formas naturais do pensamento e do discurso (VYGOTSKY, 1979, p. 74).

Segundo a perspectiva vigotskiana, o desenvolvimento humano é marcado pela dimensão histórico-cultural. As funções mentais superiores se dão do plano interpsicológico para o intrapsicológico, isto é, essas funções ocorrem primeiro na interação com os outros para, posteriormente, serem internalizadas pelo sujeito (VYGOTSKY, 1989). Dessa forma, o desenvolvimento também se apresenta em dois níveis: aquele em que o sujeito é capaz de operar sozinho e outro, no qual o sujeito é capaz de operar com o suporte de outro mais experiente. A distância entre os dois níveis é chamada de zona de desenvolvimento proximal (ZDP) $)^{5}$ que ocorre pela mediação dos outros sociais e são ferramentas psicológicas corporificadas numa outra pessoa, no signo, na brincadeira e nas situações de ensino, por exemplo. Ou ainda como afirma Tunes (1995, p. 37), "o conceito de zona proximal de desenvolvimento localiza o ponto em que a cultura e indivíduo constituem-se mutuamente".

Um mecanismo básico na função e formação da zona de desenvolvimento proximal (ZDP) é a imitação, entendida como uma atividade do sujeito, isto é, não significa uma reprodução mecânica, mas uma atividade de criação. Esta possibilita ao sujeito apropriar-se da cultura de seu grupo social, sendo um instrumento na aquisição da fala, na brincadeira e nas situações de ensino-aprendizagem (VASCONCELLOS; VALSINER, 1995).

Nos primeiros anos de vida, a brincadeira tem um papel fundamental, pois proporciona a "ação na esfera imaginativa, $[. .$.$] a criação das intenções voluntárias e a$ formação dos planos da vida real e motivações volitivas" (VYGOTSKY, 1989, p. 117). Através da brincadeira, a criança lida com imaginação e regra ao mesmo tempo, variando a forma como estas se apresentam ao longo do desenvolvimento da brincadeira infantil.

[...] toda situação imaginária contém regras de uma forma oculta, também [...] o contrário - [...] todo jogo com regras contém, de forma oculta, uma situação imaginária. O desenvolvimento a partir de jogos em que há uma situação imaginária às claras e regras ocultas para jogos com regras às claras e uma situação imaginária oculta delineia a evolução do brinquedo da criança (VYGOTSKY, 1989, p. 109).

Os estudos de Vigotski revelam que a brincadeira não se constitui em mera distração para criança, mas sim, numa atividade em que ela "a princípio pela imitação e posteriormente pela imaginação, transforma os objetos socialmente construídos e as formas de conduta em funções psicológicas intra-mentais" (VASCONCELLOS; VALSINER, 1995, p. 56-57). O brincar é considerado um elemento de suma importância para o desenvolvimento da criança nos anos pré-escolares, "que está para o desenvolvimento infantil, assim como a instrução ou o ensino está para o desenvolvimento da criança em idade escolar" (PRESTES, 2012, p. 185).

Além disso, as brincadeiras, assim como as práticas sociais cotidianas, possibilitam a formação dos conceitos espontâneos ou cotidianos que "são impregnados do concreto", pois dizem respeito às relações das palavras com os objetos a que se referem (TUNES, 1995, p. 36).

Vigotski identificou dois tipos de conceitos que operam no pensamento verbal: os conceitos cotidianos, já apresentados anteriormente, e os conceitos científicos.

\footnotetext{
${ }_{5}^{5}$ Embora reconhecendo a qualidade da crítica produzida por Zoia Prestes (2012) às publicações em língua portuguesa de Vigotski $(1979,1989)$, particularmente em relação ao conceito de "zona de desenvolvimento proximal", para os quais a pesquisadora argumenta que a tradução adequada é "zona de desenvolvimento iminente", mantivemos o termo das primeiras publicações, uma vez que este artigo foi produzido com tais referências e não realizamos um estudo mais aprofundado sobre este debate.
} 
Estes últimos se organizam em sistema hierárquico de inter-relações conceituais - sistema de relações de generalidade. São formados por meio de aquisição de um sistema de conhecimento mediado pelo ensino formal e permitem iniciar a capacidade de definição verbal, que está relacionada à capacidade de abstrair e de usar conscientemente os conceitos (TUNES, 1995). A relação entre os conceitos espontâneos e científicos ocorre em sentidos inversos: "Os conceitos científicos desenvolvem-se para baixo, através dos conceitos espontâneos; os conceitos espontâneos desenvolvem-se para cima, através dos conceitos científicos" (VYGOTSKY, 1979, p. 144). Esse tipo de movimento, portanto, difere do modelo tradicional de desenvolvimento sequencial ascendente. Para Vigotski, os diferentes tipos de pensamento verbal podem coexistir.

[...] Uma criança que atingiu formas superiores de pensamento [...] não abandona as formas mais elementares de pensamento. [...] O pensamento do adulto, muitas vezes, é realizado no nível dos complexos e chega a descer até mesmo a níveis mais primitivos (VYGOTSKY apud OLIVEIRA, M., 1995, p. 32).

O que caracteriza o pensamento infantil não é uma ausência de conhecimento que deve ser corrigido através de inculcação de informações pertinentes. As ideias infantis são leituras peculiares de mundo, inferidas a partir das relações estabelecidas com o mundo físico e social, mediadas pela cultura.

Estudos sobre a gênese da formação dos conceitos esclarecem que o "adulto não pode transmitir à criança o seu modo de pensar" (VYGOTSKY, 1979, p. 93). O fato de as crianças repetirem a informação dada por sua professora, por exemplo, não assegura que tenha havido entendimento do fenômeno, se apropriado efetivamente de um conceito.

A criança aprende muito precocemente uma grande quantidade de palavras que significam a mesma coisa para ela e para o adulto. A compreensão mútua entre o adulto e a criança cria a ilusão de que o ponto final do desenvolvimento do significado das palavras com o seu ponto de chegada, de que o pensamento é fornecido já acabado à criança desde início e que não se dá nenhum desenvolvimento (VYGOTSKY, 1979, p. 94).

Na obra de Vigotski (1979), a transmissão cultural tem valor especial e, particularmente, o ensino/instrução (educar com intencionalidade e método sistematizado). Ele reconhecia que a educação escolar deveria adotar uma pedagogia que guiasse o desenvolvimento da criança em direção às funções em processo de amadurecimento, em vez de se limitar a trabalhar apenas baseado naquilo que a criança já é capaz de fazer. Isso porque "a instrução já transmitida em determinada área pode transformar e reorganizar as outras áreas do pensamento da criança, [...] [a instrução] pode procedê-la [a maturação] e acelerar o seu progresso" (VYGOTSKY, 1979, p. 128). Nessa concepção, a transmissão cultural se dá via processos de mediação - sujeito e cultura -, portanto, as situações de ensino-aprendizagem configuram-se como áreas de desenvolvimento, as chamadas zonas de desenvolvimento proximal - ZDP (VYGOTSKY, 1989). Entretanto, lembramos que, na concepção vigotskiana, nos anos pré-escolares esse processo se dá predominantemente através de brincadeiras, uma vez que nos primeiros anos de vida a atividade mental ocorre via pensamento sincrético e por complexos, de forma que não opera com conceitos formais, científicos. A formação de conceitos, embora seja alimentada pelas informações do ambiente social, não se produz por mera transmissão (VYGOTSKY, 1989), visto que mesmo na ação de instrução, há "uma atividade autônoma da criança, que é orientada por adultos ou colegas e pressupõe, portanto, a participação ativa da criança no sentido de apropriação dos produtos da cultura e da experiência humana" (PRESTES, 2012, p. 224).

Os estudos da teoria histórico-cultural sobre pensamento, linguagem/fala e brincadeira nos primeiros anos de vida da criança trazem importantes contribuições para compreensão da pequena infância e da função da educação infantil. As ideias e conceitos histórico cultural dão fundamentos para a concepção de educação infantil afirmada nas Diretrizes Curriculares Nacionais para a Educação Infantil (DCNEI), documento legal publicado na Resolução $n^{\circ} 5$ do CNE/2009, as quais estabelecem a brincadeira e as interações como eixos norteadores das propostas pedagógicas. As interações são fundamentais se entendermos que o processo de apropriação e criação da cultura ocorre neste movimento de interpsicológico para o intrapsicológico (VYGOTSKY, 1989), em que a brincadeira tem papel fundamental nos primeiros anos de vida.

\section{Referências}

AQUINO, L. M. L. de. Creche universitária e produção do conhecimento sobre a infância. 2010. Projeto de PesquisaUniversidade do Estado do Rio de Janeiro, Rio de Janeiro, 2010. Mimeografado.

AQUINO, L. M. L. de. Infância e diversidade na produção do conhecimento nas unidades universitárias de educação infantil. 2012. Projeto de Pesquisa-Universidade do Estado do Rio de Janeiro, Rio de Janeiro, 2012. Mimeografado.

BARROS, J. F. de. Concepções de infâncias e formação continuada nas unidades de educação infantil de universidades: desafios e potencialidades. Qualificação (Doutorado em Educação)-Programa de Pós-graduação em Educação, Universidade do Estado do Rio de Janeiro, Rio de Janeiro, 2013.

BRASIL. Ministério da Educação e do Desporto. Lei $n^{\circ} 9.394$, de 20 de dezembro de 1996. Estabelece as diretrizes e bases da educação nacional. Disponível em: <http://www.planalto.gov. br/ccivil_03/leis/19394.htm>. Acesso em: 20 jul. 2013.

BRASIL. Conselho Nacional de Educação. Resolução $n^{\circ} 5$ do $C N E / C E B$, de 17 de dezembro de 2009. Fixa as Diretrizes Curriculares Nacionais para a Educação Infantil. Brasília: Diário Oficial da União, 18 de dezembro de 2009, Seção 1, p. 18.

BRASIL. Ministério da Educação. Secretaria de Educação Básica. Diretrizes curriculares nacionais para a educação infantil. Brasília: MEC, SEB, 2010.

MACHADO, M. L. A. Educação Infantil e Sócio-Interacionismo. In: OLIVEIRA, Z. M. R. de (Org.). Educação Infantil: muitos olhares. 2. ed. São Paulo: Cortez, 1995. p. 25-50. 
MELO, C. V. de. Projetos de trabalho na Creche UFF: articulação com a proposta pedagógica e a produção das crianças. 2013. Dissertação (Mestrado em Educação)Programa de Pós-graduação em Educação, Universidade do Estado do Rio de Janeiro, Rio de Janeiro, 2013.

MENEZES, F. M. de. O lugar das crianças e das infâncias na produção de conhecimento de uma Unidade Universitária de Educação Infantil. Projeto de Dissertação (Mestrado em Educação)-Programa de Pós-Graduação em Educação, Universidade do Estado do Rio de Janeiro, Rio de Janeiro, 2014.

OLIVEIRA, M. K. de. O pensamento de Vygotsky como fonte de reflexão sobre a educação. Cadernos CEDES, Campinas, n. 35, p. 9-14, 1995.

OLIVEIRA, D. R. M. de. Educação infantil em contextos rurais: perspectivas presentes na produção acadêmica recente (20002010). Qualificação (Doutorado em Educação)-Programa de Pós-graduação em Educação, Universidade do Estado do Rio de Janeiro, Rio de Janeiro, 2014.

OLIVEIRA-FORMOSINHO, J.; KISHIMOTO, T. $\quad$ M.; PINAZZA, M. A. (Org.). Pedagogia(s) da infância: dialogando com o passado, construindo o futuro. Porto Alegre: Armed, 2007.

PRESTES, Z. Quando não é quase a mesma coisa: traduções de Lev Semionovitch Vigotski no Brasil. Campinas: Autores Associados, 2012.

REIS, A. C. C. dos. Heloisa Marinho: Formação de professoras para a infância. Projeto de Dissertação (Mestrado em Educação) Programa de Pós-graduação em Educação, Universidade do Estado do Rio de Janeiro, Rio de Janeiro, 2013.

SANTOS, C. C. B. O Brincar nas produções do conhecimento da Creche UFF. 2013. Dissertação (Mestrado em Educação) Programa de Pós-graduação em Educação, Universidade do Estado do Rio de Janeiro, Rio de Janeiro, 2013.

TUNES, E. Os conceitos científicos e o desenvolvimento do pensamento verbal. Cadernos CEDES, Campinas, n. 35, p. 29-40, 1995

VASCONCELLOS, V. M. R. O lugar do conceito científico e cotidiano na construção do conhecimento da criança. VII Encontro Nacional de Educação Matemática. Rio de Janeiro: UFRJ, julho de 2001. Mimeografado.

VASCONCELlOS, V. M. R. de; VALSINER, J. Perspectiva co-construtivista na psicologia e na educação. Porto Alegre: Artes Médicas, 1995.

VYGOTSKY, L. S. Pensamento e linguagem. Tradução de M. Resende. Lisboa: Antídoto, 1979.

VYGOTSKY, L. S. A formação social da mente. Tradução: Grupo de Desenvolvimento e Ritmos Biológicos. Departamento de Ciências Biológicas - USP. 3. ed. São Paulo: Martins Fontes, 1989.

Recebido em: 29 de agosto de 2013

Aceito em: 29 de outubro de 2014 